\title{
Komparasi Model Prediksi Daftar Ulang Calon Mahasiswa Baru Menggunakan Metode Decision Tree Dan Adaboost
}

\author{
Muhammad Naufal Rabbani ${ }^{*[1]}$, Ahmad Yusuf [2], Dwi Rolliawati ${ }^{[3]}$ \\ Departemen Sistem Informasi ${ }^{[1][2][3]}$ \\ Fakultas Sains dan Teknologi \\ Universitas Islam Negeri Sunan Ampel, Surabaya, Indonesia \\ bosnaufalemail@gmail.com ${ }^{[1]}$,ahmadyusuf@uinsby.ac.id ${ }^{[2]}$,dwi_roll@uinsby.ac.id ${ }^{[3]}$
}

\begin{abstract}
Every year, all the colleges hold new student enrollment. It is needed to start a new school academic year. Unfortunately, the number of students who resigned is considerably high to reach 837 students and caused 324 empty seats. The college's stakeholders can minimize the resignation number if the selection phase of new students is done accurately. Making a machine learning-based model can be the answer. The model will help predict which candidates who potentially complete the enrollment process. By knowing it in the first place will help the management in the selection process. This prediction is based on historical data. Data is processed and used to train the model using the Adaboost algorithm. The performance comparison between Adaboost and Decision Tree model is performed to find the best model. To achieve the maximum performance of the model, feature selection is performed using chi-square calculation. The results of this research show that the performance of Decision Tree is lower than the performance of the Adaboost algorithm. The Adaboost model has f-measure score of $90.9 \%$, precision $83.7 \%$, and recall $99.5 \%$. The process of analyzing the data distribution of prospective new students was also conducted. The results were obtained if prospective students who tended to finish the enrollment process had the following characteristics: graduated from an Islamic school, 19-21 years old, parents' income was IDR $1,000,000$ to IDR. 5,000,000, and through the SBMPTN program.
\end{abstract}

Keywords- Classification, Adaboost, Ensemble Learning, Decision Tree, Enrollment

Abstrak-Pada tiap tahunnya, semua perguruan tinggi mengadakan penerimaan mahasiswa baru. Hal ini dilakukan untuk membuka tahun ajaran baru. Sayangnya jumlah mahasiswa yang mengundurkan diri cukup tinggi mencapai 837 mahasiswa dan menyebabkan adanya 324 sisa kursi kosong. Perguruan tinggi dapat meminimalisir pengunduran diri yang terjadi bila melakukan tahap seleksi calon mahasiswa baru secara tepat. Membuat model berbasis machine learning bisa menjadi salah satu jawabannya. Model dapat membantu memprediksi kandidat mana yang berpotensi melakukan daftar ulang pada proses penerimaan mahasiswa baru. Dengan mengetahui lebih awal, dapat membantu pihak manajemen dalam proses seleksi. Prediksi ini dibuat berdasarkan data yang telah ada sebelumnya. Data diolah dan digunakan untuk melatih model dengan menggunakan algoritma Adaboost. Selain itu juga dilakukan perbandingan performa dengan model algoritma Decision Tree guna mencari model terbaik. Demi mendapatkan peforma model yang maksimal, maka dilakukan proses feature selection menggunakan chi square. Hasil riset ini memperlihatkan bahwa peforma Decision Tree lebih rendah daripada algoritma Adaboost. Model Adaboost memiliki skor $f$-measure $\mathbf{9 0 . 9 \%}$, precision $83.7 \%$ dan recall $99.5 \%$. Proses analisis sebaran data calon mahasiswa baru juga dilakukan. Hasilnya didapatkan jika calon mahasiswa yang cenderung melakukan daftar ulang memiliki ciri: lulusan pondok, usia 19-21 tahun, penghasilan Orang tua Rp. 1,000,000 hingga Rp. 5,000,000, dan melalui jalur SBMPTN.

Kata Kunci-Classification, Adaboost, Ensemble Learning, Decision Tree, Enrollment

\section{PENDAHULUAN}

Berdasarkan kacamata value chain perguruan tinggi, hal yang menjadi input logistik dalam kegiatan utama perguruan tinggi adalah proses penerimaan mahasiswa baru. Awal keberhasilan perguruan tinggi dimulai dari adanya manajemen yang baik dan efektif dalam proses penerimaan mahasiswa baru [1]. Namun tidak mudah untuk melakukan seleksi calon mahasiswa baru. Ini disebabkan karena masih banyak calon mahasiswa yang lolos seleksi tapi memilih untuk mengundurkan diri. Data dari proses penerimaan mahasiswa baru di Universitas Islam Negeri Sunan Ampel Surabaya Tahun 2019 pada Tabel I mendukung pernyataan bahwa banyak calon mahasiswa baru yang tidak melakukan heregistrasi hingga tahap akhir. Hal ini menyebabkan adanya jumlah kursi kosong yang mencapai 324 kursi. Apabila jumlah kursi kosong dapat diminimalisir, maka pemasukan dari uang kuliah tunggal (UKT) bisa dimaksimalkan.

TABLE I. RANGKUMAN PAGU PENDAFTARAN TAHUN 2019

\begin{tabular}{|l|r|r|r|r|}
\hline \multicolumn{1}{|c|}{ Fakultas } & Total Pagu & $\begin{array}{c}\text { Daftar } \\
\text { Ulang }\end{array}$ & $\begin{array}{c}\text { Tidak } \\
\text { Daftar } \\
\text { Ulang }\end{array}$ & \multicolumn{1}{c|}{$\begin{array}{c}\text { Sisa } \\
\text { pagu }\end{array}$} \\
\hline Adab dan Humaniora & 460 & 434 & 69 & 26 \\
\hline Dakwah dan Komunikasi & 665 & 645 & 175 & 20 \\
\hline Ekonomi dan Bisnis Islam & 630 & 591 & 116 & 39 \\
\hline Ilmu Sosial dan Ilmu Politik & 333 & 310 & 31 & 23 \\
\hline Psikologi dan Kesehatan & 140 & 134 & 11 & 6 \\
\hline Sains dan Teknologi & 420 & 362 & 27 & 58 \\
\hline
\end{tabular}


TABLE I. RANGKUMAN PAGU PENDAFTARAN TAHUN 2019

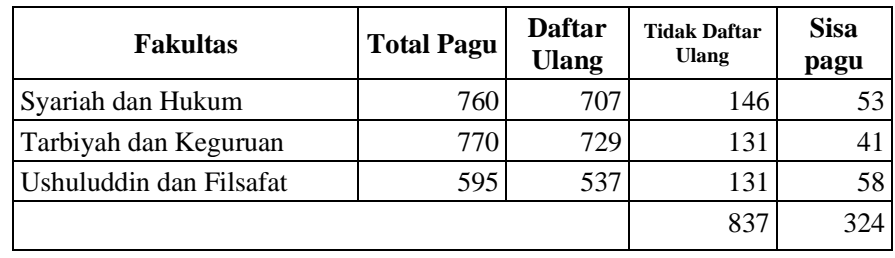

Upaya pengurangan jumlah kursi kosong dapat dilakukan dengan pendekatan data mining [2]. Salah satu fungsi data mining adalah untuk melakukan prediksi melalui klasifikasi berdasarkan data yang telah ada sebelumnya. Sehingga model prediksi ini nantinya dapat membantu proses seleksi [3]. Model akan memberi tanda pada calon mahasiswa yang berpotensi untuk mengundurkan diri dan mahasiswa yang berpotensi tinggi untuk melanjutkan hingga tahap akhir.

Data mining pada bidang pendidikan (Educational Data Mining) merupakan hal perlu dirperhatikan agar bisa menggali informasi baru yang membantu pihak penyelenggara [23]. Baik untuk kepentingan knowledge discovery maupun klasifikasi. Data yang bisa dimanfaatkan untuk proses klasifikasi diambil dari data orang tua mahasiswa, data diri mahasiswa, data demografis, dan riwayat pendidikan [4]. Klasifikasi dapat dilakukan dengan banyak metode namun metode yang umum digunakan pada Educational Data Mining (EDM) adalah Decision Tree [19].

Pada penelitian sebelumnya untuk kasus EDM, metode Decision Tree mendapat skor peforma yang lebih baik daripada metode lainnya yaitu: Logistic Regression dan Naïve bayes [5][6]. Agar meningkatkan peforma Decision Tree lebih baik lagi, dapat dilakukan Boosting menggunakan metode Adaboost. Selain mampu menambah peforma, Adaboost juga mampu mengatasi masalah data yang tidak seimbang (imbalance) sehingga prediksi yang dihasilkan menjadi lebih akurat [7][8].

Oleh karena itu, penelitian ini melakukan pembuatan model prediksi (klasifikasi) menggunakan metode Adaboost guna meningkatkan efektifitas proses penerimaan mahasiswa baru. Proses Boosting menggunakan metode Adaboost pada model Decision Tree diharapkan mampu meningkatkan peforma dari model. Model yang dihasilkan akan digunakan untuk memprediksi kandidat yang berpotensi untuk melanjutkan proses daftar ulang hingga akhir . Sehingga dengan mengetahui lebih awal, dapat membantu pihak manajemen dalam proses seleksi dan merencanakan kebutuhan sumber daya [20].

\section{METODOLOGI PENELITIAN}

Metode yang digunakan berjenis metode kuantitatif yang disesuaikan. Adapun beberapa langkah penelitian yang dilakukan untuk mencapai tujuan akhir penelitian sebagai berikut:

\section{A. Pemilihan Atribut}

Langkah paling awal adalah dengan menentukan atribut atau feature dari data yang hendak digunakan untuk proses pengembangan model prediksi. Pemilihan atribut ini diambil berdasarkan irisan dari penelitian-penlitian sebelumnya yang dipresentasikan pada Tabel II.
TABLE II. ATRIBUT TERPILIH BERDASARKAN PENELITIAN TERDAHULU

\begin{tabular}{|c|c|c|c|c|c|c|}
\hline \multirow[b]{2}{*}{ Atribut } & \multicolumn{6}{|c|}{ Penelitian Terdahulu } \\
\hline & $\begin{array}{c}\text { Wanjau \& } \\
\text { Muketha } \\
\text { [9] }\end{array}$ & $\begin{array}{c}\text { Melati, dkk } \\
{[10]}\end{array}$ & $\begin{array}{c}\text { Yahya \& } \\
\text { Jananto } \\
{[2]}\end{array}$ & $\begin{array}{c}\text { Aradea, } \\
\text { dkk. } \\
{[11]}\end{array}$ & $\begin{array}{l}R o z i \\
{[12]}\end{array}$ & $\begin{array}{c}\text { Ab Ghani, } \\
\text { dkk. } \\
{[5]}\end{array}$ \\
\hline Jenis Kelamin & $\checkmark$ & & $\checkmark$ & & & \\
\hline Usia & $\checkmark$ & & & & $\checkmark$ & \\
\hline Kota Asal & & & $\checkmark$ & $\checkmark$ & & $\checkmark$ \\
\hline Jenis Sekolah Asal & & $\checkmark$ & $\checkmark$ & & & \\
\hline Pekerjaan Orang Tua & $\checkmark$ & $\checkmark$ & & & & \\
\hline $\begin{array}{l}\text { Penghasilan Orang } \\
\text { Tua }\end{array}$ & $\checkmark$ & & & & $\vee$ & \\
\hline Fakultas & & & $\checkmark$ & $\checkmark$ & & $\checkmark$ \\
\hline Gelombang & & $\checkmark$ & & & & \\
\hline
\end{tabular}

\section{B. Pengolahan Data}

Data yang bersih dan valid tentu didapatkan melalui tahaptahap pengolahan data, yaitu: Data Validation, Data Integration and Transformation, Data Size Reduction and discretization [13]. Berikut penjelasan tahapannya:

\section{1) Data Validation}

Ekstraksi database merupakan tahap pertama yang dilakukan. Data dari ekstraksi akan menjadi input utama. Namun tidak semua data dapat langsung digunakan. Data Validation dilakukan untuk melakukan seleksi pada data dengan menghilangkan noise dan outliers. Hasil akhirnya berupa data yang konsisten dan data lengkap atau tidak ada missing value [13].

\section{2) Data Integration and Transformation}

Langkah kedua adalah melakukan transformasi data sehingga nilai dari masing-masing atribut sesuai dengan ekspektasi. Misalnya pada atribut usia, di database tidak ada kolom usia melainkan hanya tanggal lahir dan periode masuk. Jadi, pada tahap ini akan dihitung usianya berdasarkan selisih tahun masuk dengan tanggal lahir.

\section{3) Data Size Reduction and Discretization}

Tahap akhir pengolahan data adalah melakukan optimiasi pada ukuran data. Jika proses sebelumnya memerlukan kolom periode masuk untuk menghitung usia, maka pada tahap ini kolom periode masuk dihapus karena tidak termasuk atribut terpilih. Hal ini bertujuan agar mempercepat eksekusi pelatihan model yang dilakukan.

\section{Analisis Data}

Analisis dilakukan dengan menggunakan metode statistik chi square yaitu perhitungan statistik untuk mengetahui ada atau tidaknya hubungan antara dua variabel. Proses perhitungannya menggunakan library python pingouin [21]. Pemilihan metode chi square disebabkan karena jenis variabel yang ada pada dataset berjenis kategorial yang setara. Setelah mengetahui pengaruhnya, maka dapat dijadikan rujukan untuk proses pemilihan fitur (feature selection) pada proses pelatihan model. Rumus perhitungan chi square tertulis pada persamaan (1) [14].

$$
X^{2}=\sum_{i=1}^{n} \frac{\left(O_{i}-E_{i}\right)^{2}}{E_{i}}
$$


Keterangan:

$E_{i}=$ nilai ekspektasi ke-i

$O_{i}=$ nilai observasi ke-i

Namun ada beberapa syarat wajib sebelum menghitung nilai chi square dari data [14]:

- Tidak boleh ada data dengan frekuensi aktual $\left(F_{0}\right)$ yang bernilai 0 (nol).

- Jika tabel kontingensi data memiliki bentuk $2 \times 2$, maka harus tidak ada data yang memiliki nilai frekuensi harapan $\left(F_{h}\right)$ kurang dari 5.

- Jika bentuk tabel kontingensi lebih dari 2x2 (contoh: $2 \times 3$ ), maka proporsi jumlah sel dengan nilai frekuensi harapan $\left(F_{h}\right)$ kurang dari 5 tidak lebih dari $20 \%$

\section{Pelatihan Model}

Pelatihan model yang dilakukan menggunakan bahasa python dan library scikit-learn [22]. Data hasil preprocessing digunakan untuk melatih model dengan metode Adaboost yaitu teknik ensemble learning yang memiliki weak learner berupa model decision tree. weak learner (Decision Tree) yang digunakan memiliki 1 tingkat percabangan atau biasa disebut decision stump dan dilatih secara bergantian dengan data training yang sama. Tiap proses pelatihan akan memperbaiki distribusi data pada proses pelatihan selanjutnya. Sehingga meningkatkan peforma weak learner berikutnya. Iterasi akan berhenti apabila data training tidak bisa diperbaiki lagi atau apabila tercapai jumlah model maksimal [7]. Contoh alur pelatihan Adaboost dapat dilihat pada Gambar 1.

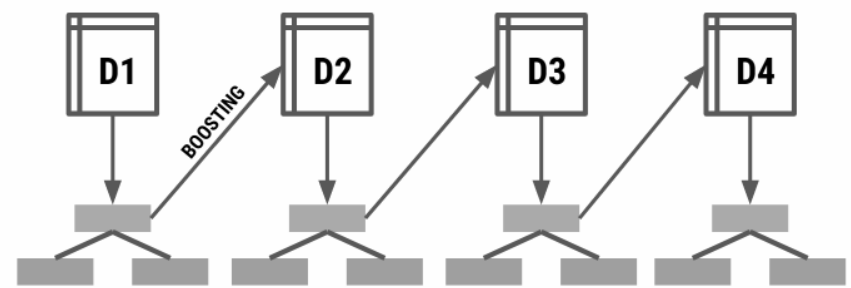

Gambar 1. Contoh alur pelatihan model Adaboost

Terdapat beberapa skenario pelatihan yang dilakukan sesuai dengan Tabel III. Penggunaan skenario seperti pada Tabel III bertujuan untuk mengetahui apakah jumlah data training mempengaruhi peforma model secara signifikan atau tidak. Skenario terbaik akan dipilih berdasarkan skor Confusion Matrix: Precision, Recall, dan F Measure tertinggi [15].

TABLE III. SKENARIO PELATIHAN MODEL

\begin{tabular}{|l|l|l|}
\hline Skenario & Data Training & Data Testing \\
\hline 1 & $70 \%$ & $30 \%$ \\
\hline 2 & $50 \%$ & $50 \%$ \\
\hline 3 & $60 \%$ & $40 \%$ \\
\hline
\end{tabular}

Confusion Matrix dapat dihitung apabila sudah diketahui hasil prediksinya. Ada beberapa kategori hasil prediksi yaitu:
True Positive (TP), True Negative (TN), False Positive (FP), dan False Negative ( $F N)$ seperti yang dijelaskan pada Tabel IV.

TABLE IV. HASIL PREDIKSI

\begin{tabular}{|l|l|l|l|}
\hline \multicolumn{2}{|l|}{ Confusion Matrix } & \multicolumn{2}{|l|}{ Kelas hasil prediksi } \\
\cline { 2 - 4 } & Positif & Negatif \\
\hline \multirow{2}{*}{$\begin{array}{l}\text { Kelas } \\
\text { Sebenarnya }\end{array}$} & Positif & TP & FP \\
\cline { 2 - 4 } & Negatif & FN & TN \\
\hline
\end{tabular}

Masing-masing skor memiliki rumus yang berbeda. Berikut adalah rumus perhitungan dari precision, recall, dan $F$-measure secara berturut-turut [16]:

$$
\begin{aligned}
& \text { Precision }=\frac{T N}{T N+F P} \\
& \text { Recall }=\frac{T P}{T P+F N} \\
& F=2 \frac{\text { Precision .Recall }}{\text { Precision }+ \text { Recall }}
\end{aligned}
$$

F-measure bukanlah hasil perhitungan mean biasa, melainkan perhitungan harmonic mean dari recall dan precision. Penggunaan harmonic mean lebih kredibel dan proporsional daripada menghitung mean biasa dalam evaluasi model [16].

\section{E. Evaluasi}

Evaluasi hasil menjadi tahap paling akhir. Pada tahap ini diambil kesimpulan berdasarkan hasil analisis data dan pelatihan model yang dilakukan. Evaluasi pada bagian analisis data menjelaskan atribut apa saja yang memiliki pengaruh terhadap status daftar ulang mahasiswa serta memaparkan ciri mahasiswa yang berpontensi daftar ulang. Sedangkan pada pelatihan model, akan dievaluasi juga pengaruh feature selection dan mencari tahu perbandingan peforma Adaboost dan Decision Tree. Tidak lupa menjelaskan skenario terbaik, dan model terbaik yang dihasilkan.

\section{HASIL DAN PEMBAHASAN}

\section{A. Pengolahan Data}

Total jumlah keseluruhan data awal yang didapat adalah 11735 data. Kemudian berkurang karena proses validasi menjadi $\mathbf{7 2 1 6}$ data. Komposisi data dipresentasikan pada Tabel $\mathrm{V}$, baik sebelum dan sesudah data diolah. Tabel V menunjukkan perbandingan jumlah data yang timpang atau tidak seimbang (imbalance) antara yang tidak melanjutkan daftar ulang dan yang melanjutkan daftar ulang setelah diolah.

TABLE V. KOMPOSISI SEBARAN DATA

\begin{tabular}{|c|c|c|c|c|c|c|}
\hline \multirow{2}{*}{ Status } & \multicolumn{3}{|c|}{ Sebelum } & \multicolumn{3}{c|}{ Sesudah } \\
\cline { 2 - 7 } & $\mathbf{2 0 1 8}$ & $\mathbf{2 0 1 9}$ & Total & $\mathbf{2 0 1 8}$ & $\mathbf{2 0 1 9}$ & Total \\
\hline Daftar Ulang & 3921 & 4444 & 8365 & 2739 & 3296 & 6035 \\
\hline Tidak Daftar Ulang & 2102 & 1266 & 3370 & 615 & 566 & 1181 \\
\hline Total Data & & & 11735 & & & 7216 \\
\hline
\end{tabular}




\section{B. Analisis Data}

Tabel VI merupakan hasil perhitungan chi square pada masing-masing atribut. Atribut dikatakan memiliki hubungan apabila nilai $p$ kurang dari $a($ alpha $=0.05)$. Berdasarkan hasil yang dipresentasikan, atribut jenis_kelamin dan pekerjaan_orang_tua tidak memiliki hubungan dengan status daftar ulang calon mahasiswa baru.

TABLE VI. HASIL PERHITUNGAN CHI SQUARE TIAP ATRIBUT

\begin{tabular}{|l|c|c|c|c|}
\hline \multicolumn{1}{|c|}{ Atribut } & chi2 & dof & p & memiliki hubungan \\
\hline usia & 12.92 & 4 & 0.012 & Ya \\
\hline jenis_kelamin & 3.638 & 1 & 0.056 & Tidak \\
\hline kabupaten_asal & 33.659 & 20 & 0.029 & Ya \\
\hline jenis_asal_sekolah & 70.622 & 10 & 0 & Ya \\
\hline pekerjaan_orang_tua & 18.492 & 14 & 0.185 & Tidak \\
\hline penghasilan_orang_tua & 35.875 & 11 & 0 & Ya \\
\hline fakultas_terpilih & 37.895 & 12 & 0 & Ya \\
\hline jalur_masuk & 158.72 & 4 & 0 & Ya \\
\hline
\end{tabular}

Meskipun ada sedikitnya 3 referensi penelitian terdahulu [2][9][10] yang menggunakan jenis kelamin dan pekerjaan orang tua sebagai atribut terpilih, penelitian ini menyatakan jika variabel jenis_kelamin dan pekerjaan_orang_tua tidak ada hubungannya dengan penerimaan mahasiswa baru karena nilai $p$ lebih besar dari nilai $a$. Hasil ini berbeda dengan penelitian [2] yang menjelaskan jika terdapat hubungan antara variabel pekerjaan orang tua dengan penerimaan mahasiswa baru. Untuk memastikan signifikansi hubungan dari kedua atribut tersebut, maka ditambahkan beberapa skenario pelatihan dengan dan tanpa atribut jenis_kelamin maupun pekerjaan_orang_tua. Model terbaik dari salah satu skenario pelatihan akan menunjukkan apakah kedua atribut tersebut lebih baik digunakan atau tidak dalam proses pelatihan model.

\section{Training Model}

Analisis data menjelaskan bahwa status daftar ulang calon mahasiswa baru tidak memiliki hubungan dengan atribut jenis_kelamin dan pekerjaan_orang_tua. Oleh sebab itu, diadakan skenario training model tambahan tanpa atribut pekerjaan_orang_tua, jenis_kelamin, maupun keduanya. Hal ini biasa disebut feature selection (FS). Dari proses training didapatkan hasil skor model Adaboost dan model Decision Tree seperti yang ditunjukkan pada Tabel VII dan Tabel VIII.

TABLE VII. SKOR TRAINING MODEL ADABOOST

\begin{tabular}{|c|c|c|c|c|c|}
\hline Scenario & $\begin{array}{c}\text { Train } \\
\text { size }\end{array}$ & $\begin{array}{c}\text { Test } \\
\text { size }\end{array}$ & F Measure & Precision & Recall \\
\hline \multicolumn{7}{|c|}{ Menggunakan semua atribut } \\
\hline 1 & $70 \%$ & $30 \%$ & 90.571792 & 83.505155 & 98.945031 \\
\hline 2 & $60 \%$ & $40 \%$ & 90.573224 & 83.321654 & 99.207343 \\
\hline 3 & $50 \%$ & $50 \%$ & 90.366059 & 83.593086 & 98.333333 \\
\hline \multicolumn{7}{|c|}{ Tanpa atribut jenis_kelamin dan pekerjaan_orang_tua } \\
\hline 1 & $70 \%$ & $30 \%$ & 90.756729 & 83.6219 & 99.222654 \\
\hline 2 & $60 \%$ & $40 \%$ & 90.63214 & 83.362522 & 99.29078 \\
\hline 3 & $50 \%$ & $50 \%$ & 90.23569 & 83.418223 & 98.266667 \\
\hline \multicolumn{7}{|c|}{ Tanpa atribut pekerjaan_orang_tua } \\
\hline 1 & $70 \%$ & $30 \%$ & 90.895257 & 83.660131 & 99.500278 \\
\hline
\end{tabular}

\begin{tabular}{|c|c|c|c|c|c|}
\hline 2 & $60 \%$ & $40 \%$ & 90.621426 & 83.432783 & 99.165624 \\
\hline 3 & $50 \%$ & $50 \%$ & 90.180483 & 83.323912 & 98.266667 \\
\hline \multicolumn{7}{|c|}{ Tanpa atribut jenis_kelamin } \\
\hline 1 & $70 \%$ & $30 \%$ & 90.651127 & 83.364399 & 99.333703 \\
\hline 2 & $60 \%$ & $40 \%$ & 90.412529 & 83.374428 & 98.748436 \\
\hline 3 & $50 \%$ & $50 \%$ & 90.398412 & 83.384962 & 98.7 \\
\hline
\end{tabular}

TABLE VIII. SKOR TRAINING MODEL DECISION TREE

\begin{tabular}{|c|c|c|c|c|c|}
\hline Scenario & $\begin{array}{c}\text { Train } \\
\text { size }\end{array}$ & $\begin{array}{c}\text { Test } \\
\text { size }\end{array}$ & F Measure & Precision & Recall \\
\hline \multicolumn{7}{|c|}{ Menggunakan semua atribut } \\
\hline 1 & $70 \%$ & $30 \%$ & 81.756757 & 82.924043 & 80.621877 \\
\hline 2 & $60 \%$ & $40 \%$ & 82.325383 & 84.080035 & 80.64247 \\
\hline 3 & $50 \%$ & $50 \%$ & 82.356937 & 83.939079 & 80.833333 \\
\hline \multicolumn{7}{|c|}{ Tanpa atribut jenis_kelamin dan pekerjaan_orang_tua } \\
\hline 1 & $70 \%$ & $30 \%$ & 81.895093 & 83.209169 & 80.621877 \\
\hline 2 & $60 \%$ & $40 \%$ & 81.717687 & 83.31166 & 80.183563 \\
\hline 3 & $50 \%$ & $50 \%$ & 82.944162 & 84.226804 & 81.7 \\
\hline \multicolumn{7}{|c|}{ Tanpa atribut pekerjaan_orang_tua } \\
\hline 1 & $70 \%$ & $30 \%$ & 82.51551 & 83.839542 & 81.232649 \\
\hline 2 & $60 \%$ & $40 \%$ & 82.283047 & 83.721934 & 80.892783 \\
\hline 3 & $50 \%$ & $50 \%$ & 82.793694 & 84.235943 & 81.4 \\
\hline \multicolumn{7}{|c|}{ Tanpa atribut jenis_kelamin } \\
\hline 1 & $70 \%$ & $30 \%$ & 81.598199 & 82.715345 & 80.510827 \\
\hline 2 & $60 \%$ & $40 \%$ & 82.312925 & 83.918509 & 80.767626 \\
\hline 3 & $50 \%$ & $50 \%$ & 82.105263 & 83.66782 & 80.6 \\
\hline
\end{tabular}

Tiap model memiliki skenario terbaiknya. Pada model Adaboost, skenario terbaiknya adalah skenario 1 tanpa menggunakan pekerjaan_orang_tua. Sedangkan pada model Decision Tree, skenario terbaiknya adalah skenario 3 tanpa menggunakan pekerjaan_orang_tua. Jika membandingkan skenario terbaik pada tiap model, maka didapatkan garfik seperti pada Gambar 2 yang menunjukkan bahwa peforma Adaboost lebih baik daripada Decision Tree.

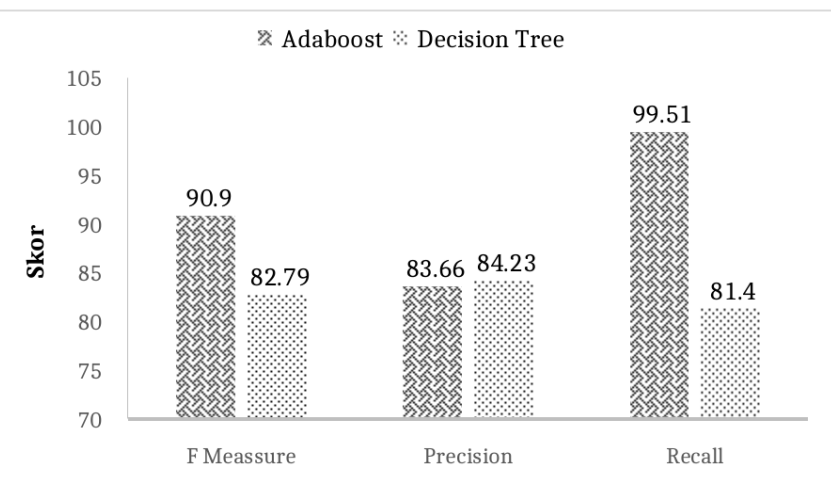

Gambar 2. Perbandingan skenario terbaik dari Adaboost dan Decision Tree

Hasil training model membuktikan bahwa proses feature selection dengan chi-square dapat meningkatkan skor metriks 
dari model sebesar $0.32 \%$ berdasarkan skor $F$-measure tertinggi dari setiap kelompok skenario. Selisihnya tidak terlalu besar atau signifikan, namun proses feature selection mengurangi jumlah atribut yang harus diproses. Hasil ini selaras dengan penelitian [13] dan berbeda dengan hasil penelitian [14] yang menjelaskan tidak adanya pengaruh proses feature selection menggunakan chi square terhadap peforma model.

Selaras dengan komparasi beberapa algoritma machine learning yang dilakukan oleh Srivastava dan Saiprasath G. dkk. menunjukkan bahwa algoritma Adaboost mengalahkan algoritma decision tree [17][18]. Hasil riset pada penelitian ini menjadi bukti tambahan bahwa Adaboost memliki peforma yang lebih baik dibandingkan dengan Decision Tree, terutama dalam kasus komposisi data yang tidak seimbang [8].

Untuk menambah pemahaman tentang model Adaboost, dilampirkan Gambar 3 yang merupakan contoh salah satu decision stump yang dihasilkan oleh model Adaboost.

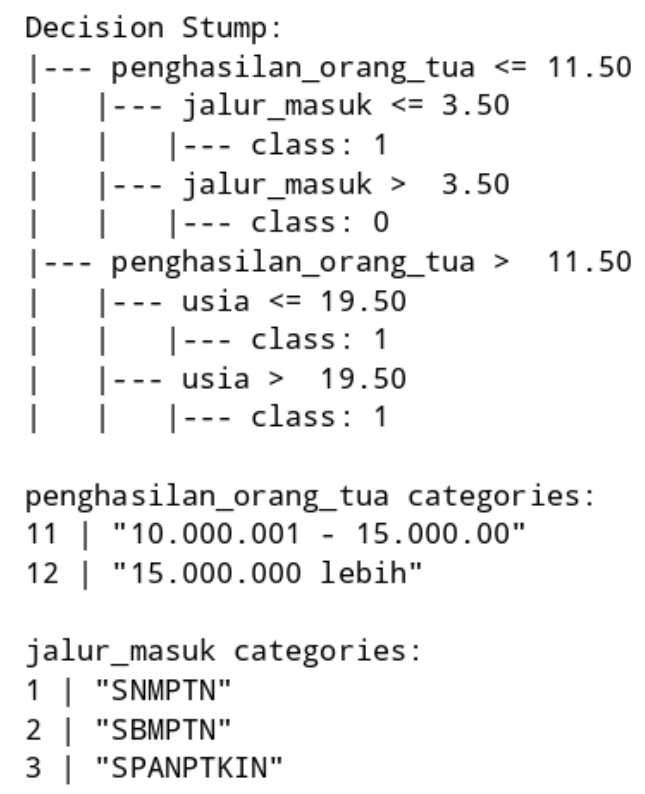

Gambar 3. Contoh decision stump dari model Adaboost

Potongan data yang ditampilkan pada Gambar 3 merupakan data yang sudah diberi label, sehingga perlu diterjemahkan agar lebih mudah untuk dipahami. Berdasarkan data yang ada, tidak ada kategori penghasilan orang tua dengan kode 11.50 yang ada hanyalah kategori 11 dan 12 . maka maksud dari penghasilan_orang_tua $<=11.50$ adalah kategori 12 yaitu 15.000.000 lebih.

Pada cabang keputusan selanjutnya, tidak ada kategori jalur masuk dengan kode 3.50 namun terdapat kategori jalur masuk 1, 2 dan 3. Maka maksud dari jalur_masuk $<=3.50$ adalah jalur masuk yang bukan dari SNMPTN, SBMPTN, dan SPANPTKIN. Sehingga apabila keseluruhan decision stump diterjemahkan akan menjadi seperti pada Gambar 4.

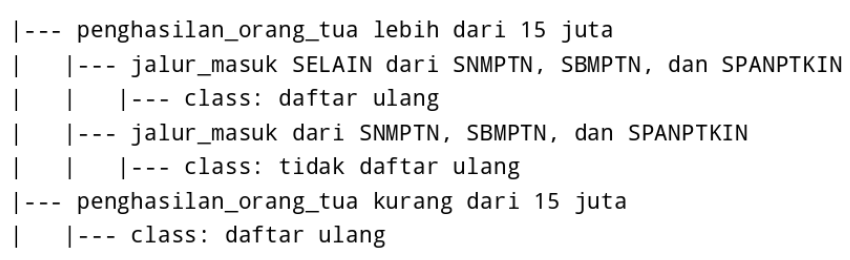

Gambar 4. Hasil terjemah decision stump Adaboost

Cara membacanya alur keputusan dari decision stump pada Gambar 4 adalah apabila calon mahasiswa memiliki data penghasilan_orang_tua lebih dari 15 juta dan masuk melalui jalur selain SNMPTN, SBMPTN, dan SPANPTKIN maka diprediksi akan melanjutkan daftar ulang hingga tahap akhir. Namun apabila penghasilan orang tua lebih dari 15 juta tapi melalui jalur SNMPTN, SBMPTN, dan SPANPTKIN maka diprediksi akan mengundurkan diri. Sedangkan mahasiswa dengan data penghasilan_orang_tua kurang dari 15 juta diprediksi daftar ulang.

\section{Observasi Sebaran Data}

Selain menghitung chi square, juga dilakukan observasi sebaran data untuk mengetahui probabilitas pada beberapa atribut berdasarkan frekuensi kemunculan dari tiap nilai (value) yang ada pada atribut. Contoh pada Tabel IX tentang atribut penghasilan_orang_tua yang memiliki 12 nilai unik berupa kategori penghasilan orang tua. Pada tiap kategori penghasilan orang tua dihitung frekuensi kemunculannya pada class daftar ulang maupun tidak daftar ulang. Lalu dihitung probabilitasnya.

TABLE IX. OBSERVASI PADA ATRIBUT PENGHASILAN ORANG TUA

\begin{tabular}{|c|c|c|c|}
\hline penghasilan_orang_tua & daftar ulang & $\begin{array}{c}\text { tidak daftar } \\
\text { ulang }\end{array}$ & $\begin{array}{c}\text { probabilitas } \\
\text { daftar ulang }\end{array}$ \\
\hline $3.000 .001-4.000 .000$ & 909 & 144 & 86.32 \\
\hline $4.000 .001-5.000 .000$ & 605 & 102 & 85.57 \\
\hline $2.500 .001-3.000 .000$ & 557 & 100 & 84.78 \\
\hline $1.500 .001-2.000 .000$ & 582 & 106 & 84.59 \\
\hline $2.000 .001-2.500 .000$ & 508 & 94 & 84.39 \\
\hline $500.001-1.000 .000$ & 630 & 121 & 83.89 \\
\hline $1.000 .001-1.500 .000$ & 766 & 148 & 83.81 \\
\hline $5.000 .001-7.500 .000$ & 582 & 125 & 82.32 \\
\hline $7.500 .001-10.000 .000$ & 299 & 65 & 82.14 \\
\hline $10.000 .001-15.000 .000$ & 112 & 26 & 81.16 \\
\hline 500.000 atau kurang & 367 & 110 & 76.94 \\
\hline 15.000 .000 lebih & 118 & 40 & 74.68 \\
\hline
\end{tabular}

Tabel IX memperlihatkan bahwa calon mahasiswa yang memiliki probabilitas di atas rata-rata $(82,54 \%)$ untuk daftar ulang adalah yang orang tuanya berpenghasilan rentang $\mathrm{Rp}$. $1,000,000$ - Rp. 5,000,000. Sedangkan yang penghasilannya $1,000,000$ ke bawah dan $15,000,000$ keatas memiliki porbabilitas di bawah rata-rata untuk melanjutkan daftar ulang.

Berdasarkan rentang usia mahasiswa baru S1 yaitu usia diantara 19 dan 21 tahun, semakin tua usia calon, maka semakin tinggi kemungkinan untuk daftar ulang. Hal ini dibuktikan pada Tabel X. 
TABLE X. OBSERVASI PADA ATRIBUT USIA

\begin{tabular}{|c|c|c|c|}
\hline usia & daftar ulang & $\begin{array}{c}\text { tidak daftar } \\
\text { ulang }\end{array}$ & $\begin{array}{c}\text { probabilitas } \\
\text { daftar ulang }\end{array}$ \\
\hline 17 & 205 & 62 & 76.78 \\
\hline 18 & 3336 & 638 & 83.95 \\
\hline 19 & 2023 & 406 & 83.29 \\
\hline 20 & 375 & 63 & 85.62 \\
\hline 21 & 69 & 8 & 89.61 \\
\hline 22 & 11 & 1 & 91.67 \\
\hline 23 & 4 & 2 & 66.67 \\
\hline 24 & 1 & 0 & 100 \\
\hline 25 & 1 & 0 & 100 \\
\hline 26 & 1 & 0 & 100 \\
\hline 39 & 9 & 1 & 90 \\
\hline
\end{tabular}

Tabel berikutnya adalah Tabel XI yang membuktikan jika calon mahasiswa dari lulusan pondok berpotensi paling tinggi untuk daftar ulang, berbeda dengan calon mahasiswa dari alumni SMAN (sekolah Menengah Atas Negeri) yang memiliki kemungkinan terkecil untuk daftar ulang.

TABLE XI. OBSERVASI PADA ATRIBUT JENIS ASAL SEKOLAH

\begin{tabular}{|c|c|c|c|}
\hline jenis_asal_sekolah & daftar ulang & $\begin{array}{c}\text { tidak daftar } \\
\text { ulang }\end{array}$ & $\begin{array}{c}\text { probabilitas } \\
\text { daftar ulang }\end{array}$ \\
\hline pondok & 52 & 3 & 94.55 \\
\hline smks & 174 & 19 & 90.16 \\
\hline pkbm & 15 & 2 & 88.24 \\
\hline smk & 117 & 18 & 86.67 \\
\hline smta & 13 & 2 & 86.67 \\
\hline ma & 216 & 35 & 86.06 \\
\hline smas & 1455 & 241 & 85.79 \\
\hline smkn & 165 & 29 & 85.05 \\
\hline man & 1297 & 231 & 84.88 \\
\hline madrasah & 77 & 14 & 84.62 \\
\hline mas & 939 & 172 & 84.52 \\
\hline sman & 1357 & 393 & 77.54 \\
\hline
\end{tabular}

Selanjutnya Tabel XII menginformasikan jika jalur SPANPTKIN menghadirkan calon mahasiswa baru dengan probabilitas daftar ulang terendah. Berbeda dengan jalur SBMPTN yang lebih banyak membawa mahasiswa yang berpotensi daftar ulang.

TABLE XII. OBSERVASI PADA ATRIBUT JENIS ASAL SEKOLAH

\begin{tabular}{|c|c|c|c|}
\hline jalur_masuk & daftar ulang & $\begin{array}{c}\text { tidak daftar } \\
\text { ulang }\end{array}$ & $\begin{array}{c}\text { probabilitas } \\
\text { daftar ulang }\end{array}$ \\
\hline SBMPTN & 1186 & 149 & 88.84 \\
\hline SNMPTN & 455 & 70 & 86.67 \\
\hline UMPTKIN & 2195 & 386 & 85.04 \\
\hline
\end{tabular}

TABLE XII. OBSERVASI PADA ATRIBUT JENIS ASAL SEKOLAH

\begin{tabular}{|c|c|c|c|}
\hline jalur_masuk & daftar ulang & $\begin{array}{c}\text { tidak daftar } \\
\text { ulang }\end{array}$ & $\begin{array}{c}\text { probabilitas } \\
\text { daftar ulang }\end{array}$ \\
\hline MANDIRI & 1460 & 272 & 84.3 \\
\hline SPANPTKIN & 739 & 304 & 70.85 \\
\hline
\end{tabular}

Tabel terakhir adalah Tabel XIII yang merupakan hasil observasi pada atribut fakultas_terpilih. Hasilnya, probabilitas paling rendah berasal dari fakultas Filsafat dan Ushuluddin, sedangkan probabilitas paling tinggi melanjutkan daftar ulang adalah fakultas Psikologi dan Kesehatan.
TABLE XIII. OBSERVASI PADA ATRIBUT JENIS ASAL SEKOLAH

\begin{tabular}{|l|c|c|c|}
\hline \multicolumn{1}{|c|}{ fakultas_terpilih } & $\begin{array}{c}\text { daftar } \\
\text { ulang }\end{array}$ & $\begin{array}{c}\text { tidak daftar } \\
\text { ulang }\end{array}$ & $\begin{array}{c}\text { probabilitas } \\
\text { daftar ulang }\end{array}$ \\
\hline Psikologi dan Kesehatan & 173 & 22 & 88.72 \\
\hline Adab dan Humaniora & 515 & 81 & 86.41 \\
\hline Ilmu Sosial dan Politik & 402 & 67 & 85.71 \\
\hline Ekonomi dan Bisnis Islam & 960 & 171 & 84.88 \\
\hline Tarbiyah dan Keguruan & 904 & 161 & 84.88 \\
\hline Dakwah dan Komunikasi & 922 & 199 & 82.25 \\
\hline Syari'ah dan Hukum & 603 & 136 & 81.6 \\
\hline Sains dan Teknologi & 470 & 111 & 80.9 \\
\hline program_magister & 182 & 46 & 79.82 \\
\hline Ushuluddin dan Filsafat & 537 & 140 & 79.32 \\
\hline
\end{tabular}

\section{KESIMPULAN}

Berdasarkan hasil pengolahan data didapatkan sebaran data yang tidak seimbang (imbalance). Namun sebaran data yang tak seimbang tersebut dapat ditangani lebih baik oleh model Adaboost daripada model Decision Tree. Hasil pelatihan model menunjukkan bahwa Adaboost memiliki peforma yang lebih baik daripada model Decision Tree dengan skor precision $83.66 \%$, recall $99.50 \%$, dan $f$-measure $90.89 \%$. Hasil riset ini menjadi bukti tambahan bahwa proses boosting dapat menambah peforma model.

Implementasikan model dapat meminimalisir jumlah kursi kosong dengan memberi tanda pada calon mahasiswa yang berpotensi untuk datar ulang maupun tidak agar dapat dipertimbangkan ulang oleh stakeholder. Analisis sebaran data yang dilakukan telah berhasil mengetahui ciri calon mahasiswa baru yang berpotensi untuk melanjutkan proses pendaftaran hingga akhir yaitu: lulusan pondok, usia 19-21 tahun, penghasilan Orang tua Rp. 1,000,000 hingga Rp. 5,000,000, dan melalui jalur SBMPTN.

\section{REFERENCES}

[1] R. K. Niswatin, "Sistem Seleksi Penerimaan Mahasiswa Baru Menggunakan Metode Weighted Product (WP)," Seminar Nasional Teknologi Informasi dan Multimedia, 2016.

[2] I. S. Melati, L. Linawati, and I. A. D. Giriantari, "Knowledge Discovery Data Akademik Untuk Prediksi Pengunduran Diri Calon Mahasiswa," JTE, vol. 17, no. 3, p. 325, Dec. 2018, doi: 10.24843/MITE.2018.v17i03.P04.

[3] P. Saini and A. Kumar Jain, "Prediction using Classification Technique for the Students\&apos; Enrollment Process in Higher Educational Institutions," IJCA, vol. 84, no. 14, pp. 37-41, Dec. 2013, doi: 10.5120/14646-2966.

[4] S. K. Wanjau and G. M. Muketha, "Improving Student Enrollment Prediction Using Ensemble Classifiers," IJCATR, vol. 07, no. 03, pp. 122128, Mar. 2018, doi: 10.7753/IJCATR0703.1003.

[5] N. L. Ab Ghani, Z. Che Cob, S. Mohd Drus, and H. Sulaiman, "Student Enrolment Prediction Model in Higher Education Institution: A Data Mining Approach," in Proceedings of the 3rd International Symposium of Information and Internet Technology (SYMINTECH 2018), vol. 565, M. A. Othman, M. Z. A. Abd Aziz, M. S. Md Saat, and M. H. Misran, Eds. Cham: Springer International Publishing, 2019, pp. 43-52.

[6] N. Yahya and A. Jananto, "Komparasi Kinerja Algoritma C 45 Dan Naive Bayes Untuk Prediksi Kegiatan Penerimaanmahasiswa Baru (Studi Kasus Universitas Stikubank Semarang)," p. 8, 2019..

[7] F. Khan, J. Ahamed, S. Kadry, and L. K. Ramasamy, "Detecting malicious URLs using binary classification through adaboost algorithm," IJECE, vol. 10, no. 1, p. 997, Feb. 2020, doi: 10.11591/ijece.v10i1.pp997$\underline{1005}$.

[8] A. N. Rais and A. Subekti, "Integrasi SMOTE Dan Ensemble AdaBoost 
Untuk Mengatasi Imbalance Class Pada Data Bank Direct Marketing," JI. Jurnal. Informatika, vol. 6, no. 2, pp. 278-285, Sep. 2019, doi: 10.31311/ji.v6i2.6186.

[9] S. K. Wanjau and G. M. Muketha, "Improving Student Enrollment Prediction Using Ensemble Classifiers," IJCATR, vol. 07, no. 03, pp. 122 128, Mar. 2018, doi: 10.7753/IJCATR0703.1003.

[10] I. S. Melati, L. Linawati, and I. A. D. Giriantari, "Knowledge Discovery Data Akademik Untuk Prediksi Pengunduran Diri Calon Mahasiswa," JTE, vol. 17, no. 3, p. 325, Dec. 2018, doi: 10.24843/MITE.2018.v17i03.P04.

[11] Aradea, Satriyo A., Ariyan Z., and Yuliana A., "Penerapan Decision Tree Untuk Penentuan Pola Data Penerimaan Mahasiswa Baru," Jurnal Penelitian Sitrotika, 2011.

[12] A. F. Rozi, "Sistem Pendukung Keputusan Seleksi Penerimaan Calon Siswa/i Baru Menggunakan Algoritma C4.5 (Studi Kasus: SDIT AnNajah Jatinom Klaten)," teknoin, vol. 21, no. 1, Feb. 2015, doi: 10.20885/teknoin.vol21.iss1.art2.

[13] Hoiriyah, "Algoritma C4.5 Berbasis Seleksi Atribut Menentukan Kemungkinan Pengunduran Diri Mahasiswa," vol. 9, p. 9, 2018.

[14] A. Nisa and E. Darwiyanto, "Analisis Sentimen Menggunakan Naive Bayes Classifier dengan Chi-Square Feature Selection Terhadap Penyedia Layanan Telekomunikasi,"p. 10, 2019.

[15] S. Amornsamankul, B. Pimpunchat, W. Triampo, J. Charoenpong, and N. Nuttavut, "A Comparison of Machine Learning Algorithms and Their Applications," International journal of simulation: systems, science \& technology, Aug. 2019, doi: 10.5013/IJSSST.a.20.04.08
[16] Y. Sasaki, "The truth of the F-measure," p. 5, Oct. 2007.

[17] A. K. Srivastava, "Comparison Analysis of Machine Learning algorithms for Steel Plate Fault Detection," vol. 06, no. 05, p. 4, 2019.

[18] Saiprasath G., Naren Babu R., ArunPriyan J., Vinayakumar R., Sowmya V., and Soman K. P., "Performance Comparison Of Machine Learning Algorithms For Malaria Detection Using Microscopic Images" IJRAR, 2019.

[19] A. A. Saa, M. Al-Emran, and K. Shaalan, "Mining Student Information System Records to Predict Students' Academic Performance," in The International Conference on Advanced Machine Learning Technologies and Applications (AMLTA2019), vol. 921, A. E. Hassanien, A. T. Azar, T. Gaber, R. Bhatnagar, and M. F. Tolba, Eds. Cham: Springer International Publishing, 2018, pp. 229-239.

[20] W. Handoko, "Prediksi Jumlah Penerimaan Mahasiswa Baru Dengan Metode Single Exponential Smoothing (Studi Kasus Amik Royal Kisaran)," Jurnal Teknologi dan Sistem Informasi, no. 2, p. 8, 2019.

[21] R. Vallat, "Pingouin: statistics in Python". Journal of Open Source Software, vol. 3, 2018, doi: https://doi.org/10.21105/joss.01026

[22] F. Pedregosa, G. Varoquaux, A. Gramfort, V. Michel, B. Thirion, O. Grisel, M. Blondel, P. Prettenhofer, R. Weiss, V. Dubourg, J. Vanderplas, A. Passos, D. Cournapeau, M. Brucher, M. Perrot, and E. Duchesnay, "Scikit-learn: Machine Learning in Python," Journal of Machine Learning Research, vol. 12, 2011, pp . 2825-2830.

[23] A. Yusuf and J. A. R. Hakim, "Pengembangan Perangkat Lunak Prediktor Nilai Mahasiswa Menggunakan Metode Spectral Clustering dan Bagging Regresi Linier," vol. 1, p. 5, 2012. 